\title{
Bee venom treatment reduced C-reactive protein and improved follicle quality in a rat model of estradiol valerate-induced polycystic ovarian syndrome
}

Karimzadeh L (1), Nabiuni M (1), Sheikholeslami A (1), Irian S (1)

(1) Department of Cell and Molecular Biology, School of Biological Sciences, Kharazmi University, Tehran, Iran.

\begin{abstract}
Polycystic ovarian syndrome (PCOS) is a low grade inflammatory disease characterized by hyperandrogenemia and chronic anovulation. C-reactive protein (CRP), released by adipocytes, plays a key role in PCOS. Apis mellifera honeybee venom (HBV) contains a variety of biologically active components with various pharmaceutical properties. This study was designed to assess the possibility of HBV application as an anti-inflammatory therapeutic agent. To induce PCOS, $1 \mathrm{mg} / 100 \mathrm{~g}$ body weight estradiol valerate (EV) was subcutaneously (SC) injected into eight-week-old rats. After 60 days, $0.5 \mathrm{mg} / \mathrm{kg} \mathrm{HBV}$ was administered SC for 14 consecutive days, and the results of PCOS treatment were investigated. Rats were then anesthetized with chloroform, and their ovaries and livers were surgically removed to determine histomorphometrical changes. Testosterone and 17- $\beta$-estradiol were detected by chemiluminescence immunoassay. In order to detect serum CRP, ELISA kit was used in three groups of EV-induced PCOS, HBV-treated PCOS and control animals. Thickness of the theca layer, number of cysts and the level of serum CRP significantly decreased in HBV group in comparison with PCOS group. Moreover, corpus luteum, as a sign of ovulation, was observed in HBV-treated ovaries which were absent in PCOS group. Our results suggest that the beneficial effect of $\mathrm{HBV}$ may be mediated through its inhibitory effect on serum CRP levels.
\end{abstract}

Key words: polycystic ovarian syndrome (PCOS), honeybee venom (HBV), C-reactive protein (CRP), estradiol valerate (EV), corpus luteum, chemiluminescence immunoassay.

\section{INTRODUCTION}

Polycystic ovarian syndrome (PCOS) is one of the most common causes (70\%) of anovulatory infertility (1). It accounts for $20 \%$ of infertility cases amongst couples, and up to $10 \%$ of reproductive age women are diagnosed with this endocrine disorder, discovered first by Luntal and Estein in 1935. Even though the term polycystic ovarian syndrome disease (PCOD) is used for this disorder, PCOS is more common, due to heterogeneous clinical signs such as hirsutism, oligomenorrhea and amenorrhea, hyperandrogenism and ovarian histopathological disorders. Histological features of ovaries in PCOS include the presence of more than 12 follicles with a size smaller than $10 \mathrm{~mm}$, surrounding the stroma, and an increase in the thickness of follicular theca and the ovarian stromal volume $(1,2)$.

PCOS and the metabolic syndrome have several features in common, such as obesity, hyperinsulinemia, insulin resistance, glucose abnormalities predictive of type 2 diabetes mellitus, dyslipidemia and hypertension (3). Nonalcoholic steatohepatitis, caused by insulin resistance, obesity, diabetes mellitus, and/or hypertriglyceridemia, is associated with a change in hepatocyte lipids, hepatocyte ballooning necrosis, neutrophil infiltration and the 
development of a particular type of fibrosis and lobular bile infarctions (4).

One-third of PCOS women are obese, as obesity increases the likelihood of a woman with the syndrome developing anovulation increases (5). About $40 \%$ of obese PCOS women have similar diagnostic criteria for impaired glucose tolerance or type 2 diabetes by age 26 . PCOS patients have three-fold increased prevalence of hypertension compared with regularly menstruating women $(6,7)$. A higher risk of myocardial infarction in PCOS patients compared with age-matched controls has been observed. About half of PCOS patients have polycystic ovaries (PCO) and more frequently exhibit coronary artery segment with stenosis greater than $50 \%$ and more severe ischemic heart disease (IHD) than women with normal ovaries (8).

C-reactive protein (CRP) which was first detected in 1930 by Tillet and Frances belongs to the pentraxin family of calcium-dependent ligand-binding plasma proteins, found in most vertebrates (e.g. mice, rats, and humans) (9). CRP binds to pneumococcal C-polysaccharide (CPS) in humans; whereas in nonhumans, CRP binds to the surface of dead or dying cells (10). CRP which was first detected in 1930 by Tillet and Frances belongs to the pentraxin family of calcium-dependent ligand-binding plasma proteins, found in most vertebrates (e.g. mice, rats, and humans) (9). The physiological role of CRP is to activate the complement system via the C1Q complex. C-reactive protein is a marker of inflammation, which is usually increased in PCOS patients, and this high CRP level may explain the reason for increased risk for development of earlyonset cardiovascular disease (CVD) in some PCOS women, who without any other chronic disease may be in high risk for CVD in comparison with women at similar age and body mass index (BMI) $(11,12)$.

PCOS women, who are at high risks of developing type II diabetes and CVD, may show different levels of CRP compared with the controls (6). Hyperinsulinemia associated with high CRP levels may cause cardiovascular diseases which additionally can result in the development of PCOS. In fact, CRP levels have been considered signs for detecting vascular events. The increased expression levels of adipose tissue-derived cytokine (tumor necrosis factor- $\alpha$ and interleukin-6) may mainly be involved in low grade chronic inflammation. In other words, adipose tissue may play an important role in developing features of the metabolic syndrome and low grade chronic inflammation $(12,13)$.

Bee venom is constituted of a large number of complex molecules. Certain components, especially melittin, apamin and peptide 401, have been widely investigated as to reveal their physiological effects, to discover their compatibility upon different anti-inflammatory mechanisms. The reduced expression of cyclooxygenase (COX)-2 and phospholipase (PL) $\mathrm{A} 2$ and the decreased levels of tumor necrosis factor alpha (TNF- $\alpha$ ), interleukin (IL)-1, IL-6, nitric oxide (NO) and reactive oxygen species (ROS) are suggested to be associated with the anti-arthritis effects of melittin. Adolapin also has anti-inflammatory property in carrageenaninduced edema and polyarthritis rats (14). The effects of adolapin are presumably due to its ability to inhibit the prostaglandin (PG) synthesis through COX inhibitory properties. Apamin, a small conductance $\mathrm{Ca}^{2+}$-activated $\mathrm{K}^{+}$channel blocker, significantly inhibited both ovalumineinduced tracheal contraction and histamine release from lung tissues, suggesting that this compound reduces allergic airway inflammation through a mast cell stabilizing effect. The mast cell degranulating (MCD) peptide has an anti-allergic activity by inhibiting the release of histamine from mast cells (15).

In the present study, we provide evidence of a direct involvement of inflammation in the maintenance and progression of PCOS. In fact, in addition to the direct involvement of $\mathrm{EV}$ in the formation of cysts, the development of PCOS could have an inflammatory effect on liver, and lead to the degeneration of liver stroma and cells. Clinical observations also suggest that PCOS is associated with inflammation and an increase in serum CRP and liver damage. Thereupon, according to the anti-inflammatory effects of bee venom on arthritis and other inflammatory diseases, we hypothesized that bee venom may decrease the incidence of PCOS, as an inflammatory disease.

In order to test such hypothesis, we evaluated the serum CRP levels in normal rats, and concerning the close relationship between PCOS, systemic inflammation and metabolic syndrome, we compared serum CRP levels in normal and PCOS animals. To discover the antiinflammatory effects of honey bee venom and its 
inhibitory effect on NF- $\mathrm{BB}$ signaling pathway, we investigated serum CRP alterations in HBVtreated PCOS animals as an inflammation index, and eventually, the hormonal and histological changes in ovary and liver in HBV-treated PCOS rats were compared with those in PCOS animals.

\section{MATERIALS AND METHODS}

Experiments were performed on adult female Wistar rats $(170 \pm 20 \mathrm{~g})$ provided by Kharazmi University, Tehran, Iran. Before and during the experiments, animals were housed in special cages with a standard space, under controlled light/dark cycle (lights on from 06:00 to 20:00). Humidity and temperature were set at $55 \pm 15 \%$ and $20-24^{\circ} \mathrm{C}$, respectively, and free access to water and commercial food (Behparvar Com., Iran) was provided. All procedures were carried out according to the Guide for the care and use of laboratory animals (16).

In this experiment, rats with a 2-3 estrous cycle period within a twelve to fourteen day interval were used. PCOS rats were selected on the basis of displaying a minimum of two continuous estrous cycles. Rats were in the estrous stage of their reproduction cycle.

Initially, animals were divided into three groups (of ten individuals each): controls (no injection), PCOS $[2 \mathrm{mg}$ of estradiol valerate (Aburaihan Co. Iran) via intramuscular injection] and sham 1 (a similar dose of sesame oil with no estradiol content) (17). All animals were under vaginal smear analysis for a period of 60 days until the appearance of persistent vaginal cornification (PVC), a sign of follicular cysts in the ovary. After verifying the induction of PCOS, the PCOS group was divided into two subgroups: PCOS and PCOS+HBV. PCOS+HBV received $0.5 \mathrm{mg} /$ $\mathrm{kg}$ HBV SC for 14 consecutive days, while PCOS (i.e., sham 2) group received physiological saline solution (18). Sham 1 and sham 2 groups were later deleted due to their lack of any difference from the control.

At around 9 a.m. rats were weighed and anesthetized with chloroform, the trunk blood was collected, and the serum samples were separated using a $6,000 \mathrm{rpm}$ centrifugation for five minutes. Samples were kept at $-20^{\circ} \mathrm{C}$ for later serological experiments. Ovaries were separated from the twisted oviduct tubes, weighed and fixed in a dish containing PBS solution. Fatty tissue was separated under a loop microscope.

Serological analysis was performed to measure serum CRP levels and hormonal alterations. Serum testosterone and estradiol levels were determined by chemoluminesance immunoassay (CLIA) (DiaSorin comany, Italy). In order to detect serum CRP, ELISA kit (Millipore's MILLIPLEX ${ }^{\oplus}$ MAP Rat/Mouse CRP Single Plex, USA) was used.

\section{Ovary and Liver Histological Sections}

Ovaries and livers were placed in Bouin's fixative for histological analysis; fixed samples were kept in alcohol solutions of 20 to $100 \%$ for a period of 45 minutes to dehydrate, and later in alcohol/xylen (50:50) and xylen (three times) for clearing, and finally blocked in paraffin. Samples were sliced to sections of 7 micron thickness using a microtome and then placed on slides, previously coated with gelatin, prior to staining with hematoxylin-eosin for histological observations. In order to determine follicular development, follicles were classified based on morphology and diameter into six groups of primordial, primary, preantral (all with $<600$ $\mu \mathrm{m}$ in diameter), antral (with 600-1000 $\mu \mathrm{m}$ in diameter), cystic follicles and corpus luteum.

\section{Statistical Analysis}

The one-way ANOVA and InStat software were used to determine the statistical significance of differences between the values for the experimental and control groups. Data were expressed as means \pm standard error (SEM), and the results were taken from at least three independent experiments, performed in triplicates. Values of $\mathrm{p} \leq 0.05$ were considered statistically significant.

\section{RESULTS}

\section{Body Weight}

In order to evaluate the metabolic changes in rats, animals were divided into three groups of control, PCOS and Apis melifera bee venomtreated (HBV-treated), and weighed. In addition to a significant increase in body weight of the PCOS group, an increase in adipose tissue of the abdominal cavity was macroscopically detected. On the other hand, in HBV-treated group, a decrease in both abdominal adipose tissue and 
total body weight was macroscopically detected which was not significant (Table 1).

\section{Ovarian Weight}

A significant increase in the weight of the ovaries was detected in PCOS group compared with control. Furthermore, in HBV-treated group a significant decrease in ovary weight was observed compared with PCOS group (Table 1).

\section{Hormone assay}

CLIA showed a significant increase in the levels of both testosterone and estradiol in PCOS group. However, progesterone levels did not decrease significantly. These three hormones were decreased in animals treated with the bee venom. The reduction observed in testosterone and estradiol levels in HBV-treated animals were significant. A significant difference was also observed in progesterone levels in HBV-treated group compared with the polycystic group, which was due to corpus luteum formation in the ovaries of the former. These data, in particular the increase in androgen (i.e., testosterone) levels, demonstrate the success of PCOS induction, and that bee venom reduced estradiol and testosterone levels (Table 1).

\section{CRP assay}

In general, within six hours, serum CRP level starts increasing, and peaks in 48 hours. Twentyfour hours following the disappearance of inflammation, its level drops by $50 \%$, whereas in chronic inflammation, due to the prolonged half time, it remains high. Therefore, serum CRP level fundamentally adjusts its own production, which in this study, PCOS induction led to a significant raise in this systemic inflammatory index, and its reduction in rats treated with $\mathrm{HBV}$ was significant (Table 1).

\section{Ovary and Liver Histological Sections}

A significant decrease was observed in the number of primary follicles, antral follicles, corpus luteum, primordial follicles and preantral follicles in PCOS ovaries. In addition, some large cystic follicles with a thin granolusa layer of 2-3 cell layers were observed. In this group, no corpus luteum, as a sign of ovulation, was detected. In the sham group, ovaries contained no cyst but several follicles at different stages of development, and also corpus luteums were distinguishable. These results were indicative of a complete induction of the PCOS phenotype.

In rats treated with $\mathrm{HBV}$, the number of primordial and preantral follicles and corpus

Table 1. Bee venom treatment effects in polycystic ovarian syndrome (PCOS). Baseline parameters of PCOS rats $(n=10)$ and controls $(n=10)$ and bee venom-treated rats $(n=10)$

\begin{tabular}{c|c|c|c|c|c|c}
\hline Measured Parameters & C & P & P+BV & C vs. P & $\begin{array}{c}\text { C vs. } \\
\text { P+BV }\end{array}$ & $\begin{array}{c}\text { P vs. } \\
\text { P+BV }\end{array}$ \\
\hline Serum estradiol $(\mathrm{pg} / \mathrm{mL})$ & 14.5 & 54.778 & 21.889 & $* * *$ & $*$ & $* * *$ \\
\hline Serum testosterone $(\mathrm{ng} / \mathrm{dL})$ & 62.5 & 345.9 & 115.9 & $* * *$ & Ns & $* * *$ \\
\hline Serum progesterone $(\mathrm{ng} / \mathrm{mL})$ & 28 & 24 & 40 & $\mathrm{~ns}$ & $* *$ & $* *$ \\
\hline Serum CRP $(\mathrm{ng} / \mathrm{mL})$ & 70.4 & 83.4 & 72.4 & $* *$ & Ns & $*$ \\
\hline Ovarian weight $(\mathrm{mg})$ & 13 & 20.5 & 15 & $* *$ & Ns & $*$ \\
\hline $\begin{array}{c}\text { Body weight }(\mathrm{g}) \\
\text { Preantral follicle theca layer thickness }(\mu \mathrm{m})\end{array}$ & 207.1 & 217.1 & 214 & $* *$ & $*$ & Ns \\
\hline $\begin{array}{c}\text { Early antral follicle theca layer thickness } \\
(\mu \mathrm{m})\end{array}$ & 71.7 & 123.4 & 93.7 & $* * *$ & $*$ & $* * *$ \\
\hline $\begin{array}{c}\text { Late antral follicle theca layer thickness } \\
(\mu \mathrm{m})\end{array}$ & 99.8 & 157.2 & 110.7 & $* * *$ & $\mathrm{~ns}$ & $* *$ \\
\hline
\end{tabular}

C: control rats; P: PCOS rats; P+BV: BV-treated PCOS rats; ${ }^{*} p<0.05 ;{ }^{* *} p<0.01 ;{ }^{* * *} p<0.001$; ns: not significant. 


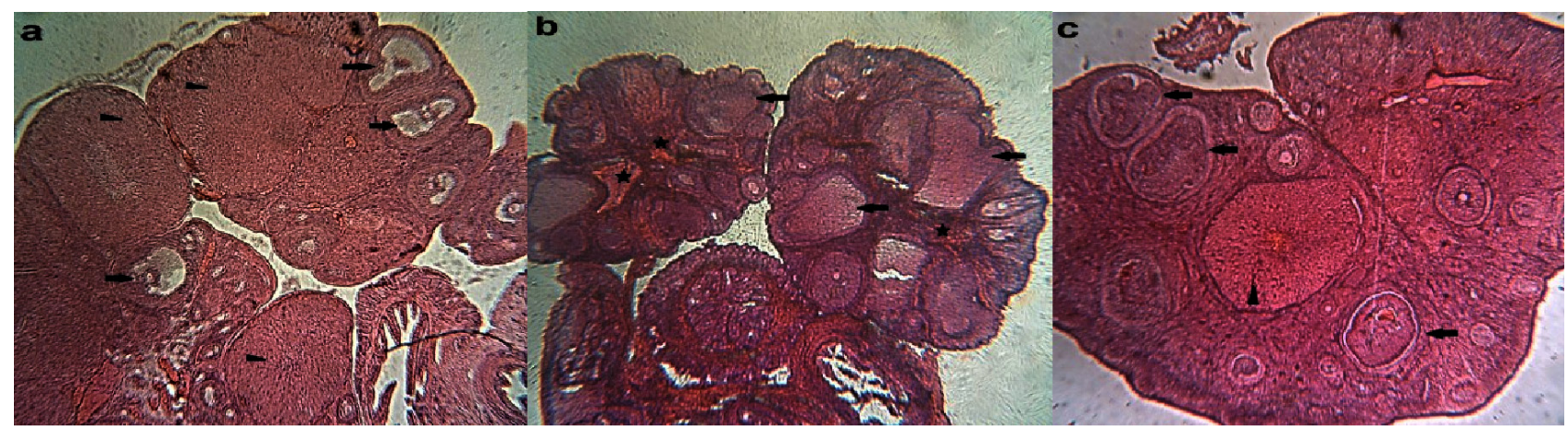

Figure 1. Histological analysis showing (a) normal, (b) PCOS and (c) BV-treated PCOS ovaries. Ovarian sections were stained with hematoxylin and eosin. An increase in the number of cysts (arrow), lack of corpus luteum (arrow head), and increased levels of ovarian stroma (star) in panel $\mathbf{b}$ is compared with panel $\mathbf{a}$. In panel $\mathbf{c}$, a decrease in the number of cysts and the ovarian stroma level, and the appearance of a corpus luteum can be detected.

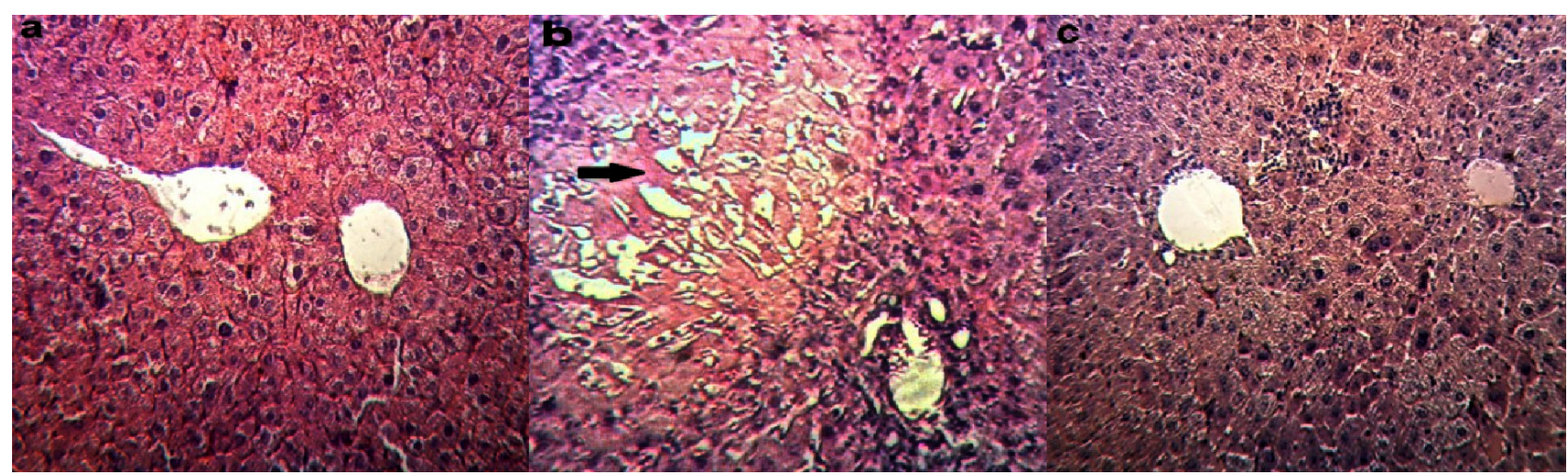

Figure 2. Liver sections from (a) normal, (b) PCOS and (c) BV-treated PCOS rats. Liver sections were stained with hematoxylin and eosin. Arrow points to a necrotic area in the PCOS liver.

luteums increased, whereas the number of cysts decreased significantly compared with the sham group. In addition, some corpus luteums were observed in the HBV group, which was considered a sign of relative improvement in PCOS ovaries (Table 1, Figures 1, 2, 3 and 4).

\section{DISCUSSION}

The mechanism for the association between PCOS and the metabolic syndrome has been the subject of intense investigation, since it was first described in 1980 (19).

CRP is known as an important marker of inflammation, and its concentration is directly related to insulin resistance, increase in body weight, adipose body mass and lipid profile $(11,12)$. In the present study, the levels of testosterone, estrogen and BMI were evaluated, and it was demonstrated that an increase in serum testosterone level, as a sign of PCOS, occurs as a result of increased serum CRP levels. Liu et al. (20) reported that CRP induces TNF- $\alpha$ secretion through p38 MAPK-TLR4 signaling pathway in rat vascular smooth muscle cells. Spaczynski et al. (21) demonstrated that TNF-a causes the proliferation and differentiation of theca cells. Based on these reports and the study results, it can be speculated that increased serum CRP levels may have caused an increase in TNF- $\alpha$ expression which in turn would have stimulated the proliferation, androgenesis and steroidogenesis of follicular layer cells. In addition to CRP, adipose tissue may have also led to increased TNF production (22).

Androgens can lead to increased lipolysis and 


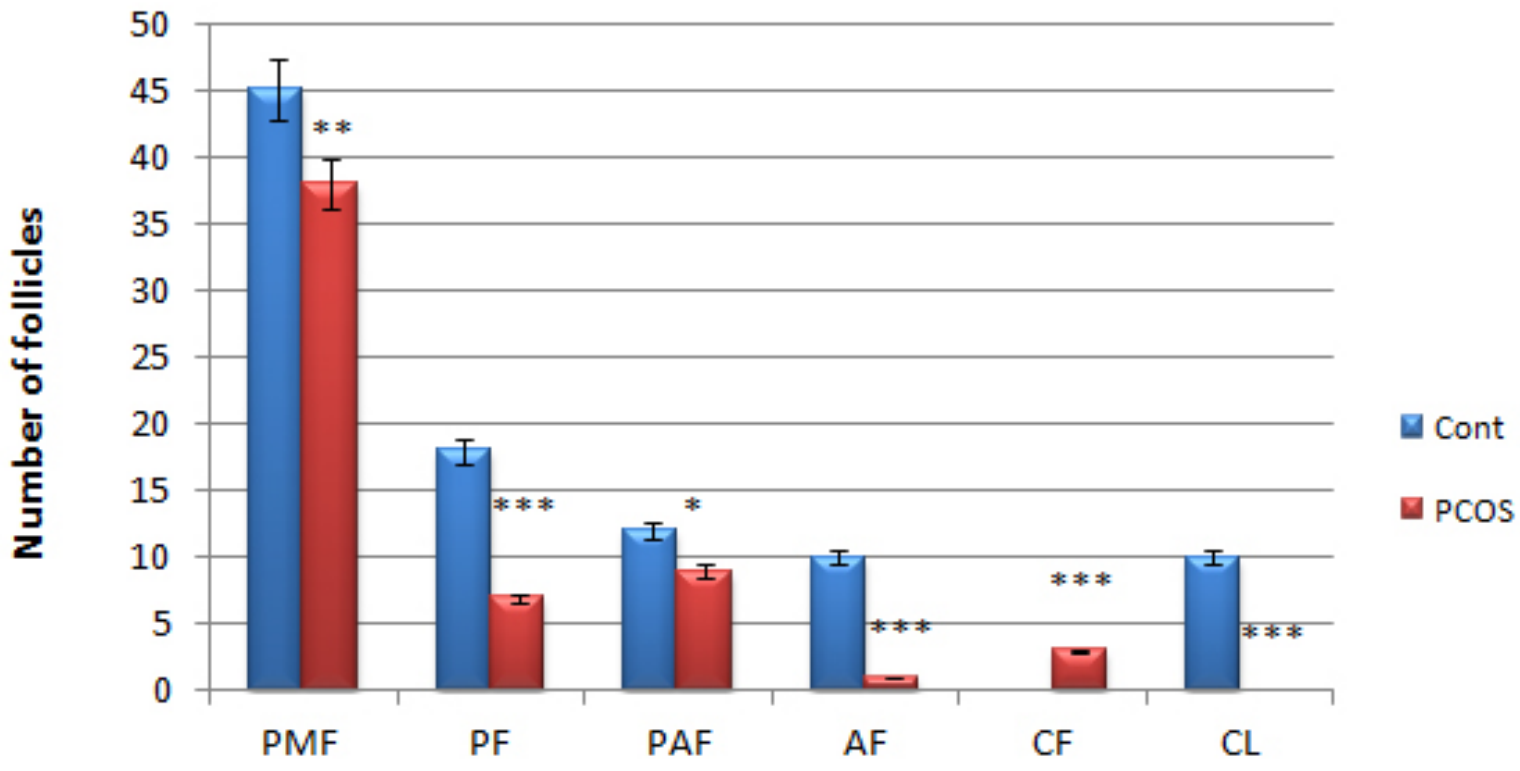

Groups of follicles

Figure 3. Different follicular groups in control and PCOS ovaries $(n=10)$. Note the increase in the numbers of cysts and a decrease in the number of corpora lutea of PCOS ovaries, respectively. PMF: primordial follicle; PF: primary follicle; PAF: preantral follicle, AF: antral follicle; CF: cystic follicle; CL: corpus luteum; ${ }^{* * *} \mathrm{p}<0.001 ;{ }^{* *} \mathrm{p}<0.01 ;{ }^{*} \mathrm{p}<0.05$.

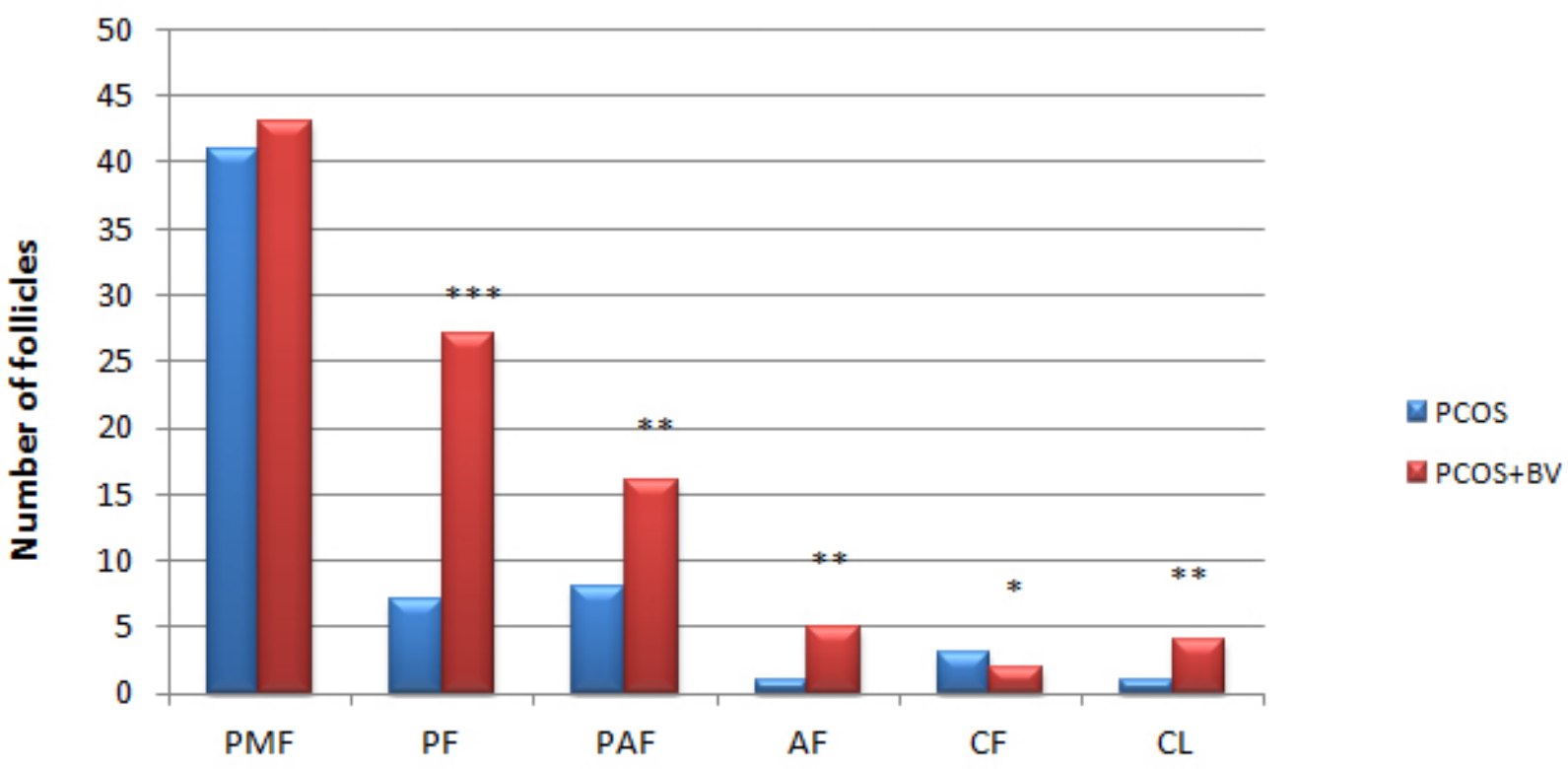

Groups of follicles

Figure 4. Different follicular types in the ovaries of PCOS and BV-treated PCOS rats. A significant increase in all follicular clusters is detected in BV-treated PCOS ovaries $(n=10)$, (except primordial follicles). Moreover, a significant decrease in the number of ovarian cysts is also detected. PMF: primordial follicle; PF: primary follicle; PAF: preantral follicle, AF: antral follicle; CF: cystic follicle; $C L$ : corpus luteum; ${ }^{* *} p<0.001 ;{ }^{* *} p<0.01$. 
a consequent increase in free fatty acid levels. Free fatty acids have also been shown to increase obesity. Free fatty acids are the primary ligands for toll like receptors, the central regulators for innate immune responses. Therefore, free fatty acids act as direct links between obesity and inflammation (7). Obesity is a chronic systemic inflammation, which is associated with increased serum levels of inflammatory cytokines. It was believed that body mass index is correlated with high serum CRP levels. However, recent studies have reported that adiposity is related to serum CRP levels. This is the reason why it can be considered that the adipose tissue-derived cytokine expression (TNF- $\alpha$ and ILs) is an important factor in low grade chronic inflammation. Indeed, the accumulation of adipose tissue may be involved in the development of the metabolic syndrome and low grade chronic inflammation $(6,11,12)$. TNF- $\alpha$ is a cytokine produced by several cell types including lymphocytes and macrophages around the bile ducts, and can induce cell death when triggered (23). Here as a complementary study, the integrity of liver tissue was evaluated, since liver undergoes cell damage in inflammatory conditions. Cell death was distinguishable in liver slides of PCOS rats near ducts, and not in any sections of the control or the bee venom-treated groups. Therefore, it is also likely that the anti-inflammatory effects of bee venom could be detected in the liver; however, this claim needs further research.

On the other hand, raising androgen levels result in an increase in the hypertrophy of adipocytes, and by also affecting the expression of enzymes and proteins involved in the metabolism of carbohydrates and lipids, result in the oxidative stress and differentiation of pre-adipocytes to mature adipocytes $(22,24)$. Based on the fact that the inflammatory cytokines are the products of adipocytes, an increase in serum CRP (a cytokine) along with increased testosterone levels and body weight, detected in the present study, could be all indicative of a possible increase in adipocytes in PCOS rats (25).

An increase in NF- $\mathrm{BB}$ expression activates ovarian steroidogenesis enzymes leading to an increase in testosterone and androstenedione levels (22). Considering PCOS as an inflammatory disorder, decreasing androgen levels may lower the incidence of PCOS through a reduction in serum CRP level (the inflammatory marker), mediated by the bee venom.
Bee venom has an anti-inflammatory effect stronger than $\mathrm{n}$-hexane and ethyl acetate (26). Bee venom inhibits the DNA-binding activity of NF- $\kappa B$ by inhibiting I $\kappa B$ phosphorylation (14). Thus, our findings are in agreement with those of others showing that the anti-inflammatory activity of honey bee venom is mediated through suppression of the NF- $\kappa \mathrm{B}$ signaling pathway (27, 28). So, increased levels of CRP can be adjusted by treating rats with honey bee venom for 14 days. We show that bee venom by CRP inhibition causes regression of PCOS in an animal model. Metformin, which is considered the main treatment for PCOS, has been shown to inhibit $\mathrm{NF}-\kappa \mathrm{B}$ activation, and reduce serum CRP levels in PCOS women $(1,29,30)$.

Histological changes observed in PCOS ovary following bee venom treatment can also be considered a confirmation for the progression of the syndrome. This study shows for the first time that bee venom causes a decrease in the thickness of the follicular theca layer in PCOS rats, possibly mediated through increased lipolysis and decreased hypertrophy of this layer. Due to this decrease, the androgens and steroids produced by this layer would also decrease.

\section{CONCLUSION}

Due to the anti-inflammatory effects and the ability to reduce metabolic features, HBV has been able to increase the reproduction rate in PCOS rats through a reduction in ovary cysts and an increase in the appearance of corpus luteum. Therefore, HBV can alter both reproductive and the metabolic features of PCOS. Furthermore, we speculate that this effect of $\mathrm{HBV}$ is mediated through suppression of the NF- $\kappa \mathrm{B}$ signaling pathway

\section{ACKNOWLEDGMENTS}

The authors are grateful to Kharazmi University for providing the necessary materials.

\section{COPYRIGHT}

(C) CEVAP 2012

\section{SUBMISSION STATUS}

Received: May 21, 2012.

Accepted: August 15, 2012.

Abstract published online: September 3, 2012.

Full paper published online: November 30, 2012. 


\section{CONFLICTS OF INTEREST}

The authors declare no conflicts of interest.

\section{FINANCIAL SOURCE}

Kharazmi University, Tehran, Iran, provided the required materials for the present study.

\section{CORRESPONDENCE TO}

Mohammad Nabiuni, School of Biological Sciences, Department of Cell and Molecular Biology, Kharazmi University (Tarbiat Moallem University), Karaj, Iran, Postal Code: 3197937551. Phone: +98 9126609337. Email: devbiokharazmi@gmail.com.

\section{REFERENCES}

1. Diamanti-Kandarakis E, Paterakis T, Alexandraki K, Piperi C, Aessopos A, Katsikis I, et al. Indices of low-grade chronic inflammation in polycystic ovary syndrome and the beneficial effect of metformin. Hum Reprod. 2006;21(6):1426-31.

2. Baravalle C, Salvetti N, Mira G, Pezzone N, Ortega H. Microscopic characterization of follicular structure in letrosole-induced polycystic ovarian syndrome in the rat. Arch Med Res. 2006;37(7):830-9.

3. Apridonidze T, Essah PA, Iuorno MJ, Nestler JE. Prevalence and characteristics of the metabolic syndrome in women with polycystic ovary syndrome. J Clin Endocrinol Metab. 2005;90(4):1929-35.

4. Marra F. Chemokines in liver inflammation and fibrosis. Front Biosci. 2002;7:d1899-914.

5. Panidis D, Kita M, Katsikis I, Karkanaki A, Karayannis V, Rousso D. Mechanisms of infertility in polycystic ovary syndrome. Aristotle University Med J. 2006;33(2):67-77.

6. Boulman N, Levy Y, Leiba R, Shachar S, Linn $\mathrm{R}$, Zinder $\mathrm{O}$, et al. Increased $\mathrm{C}$ - reactive protein levels in the polycystic ovary syndrome: a marker of cardiovascular disease. J Clin Endocrinol Metab. 2004; 89(5):2160-5.

7. Sathyapalan T, Atkin L. Mediators of Inflammation in polycystic ovary syndrome in relation to adiposity. Mediators Inflamm. 2010;758656.

8. Barutcuoglu B, Bozdemir E, Dereli D, Parildar Z, Mutaf I, Ozmen D, et al. Increased serum neopterin levels in women with polycystic ovary syndrome. Ann Clin Lab Sci. 2006;36(3):267-72.

9. Li JJ, Fang CH. C-reactive protein is not only an inflammatory marker but also a direct cause of cardiovascular diseases. Med Hypotheses. 2004;62(4):499-506.

10. Diaz Padilla N, Bleeker WK, Lubbers Y, Rigter GM, Van Mierlo GJ, Daha M, et al. Rat C-reaction protein activates the autologous complement system. Immunology. 2003;109(4):564-71.

11. Ridker PM, Hennekens $\mathrm{CH}$, Burging JE, Rifai N. $\mathrm{C}$-reactive protein and other markers of inflammation in the prediction of cardiovascular disease in women.
New England J Med. 2000;342(12):836-43.

12. Benson S, Janssen O, Hahn S, Tan S, Dietz T, Mann $\mathrm{K}$, et al. Obesity, depression, and chronic low-grade inflammation in women with polycystic ovary syndrome. Brain Behav Immun. 2008;22(2):177-84.

13. Kelly CC, Lyall H, Petrie JR, Gould GN, Connell JM, Sattar N. Low grade chronic inflammation in women with polycystic ovarian syndrome. J Clin Endocrinol Metab. 2001;86(6):2453-5.

14. Park HJ, Son DJ, Lee CW, Choi MS, Lee US, Song HS, et al. Melittin inhibits inflammatory target gene expression and mediator generation via interaction with IkappaB kinase. Biochem Pharmacol. 2007;73(2):237-47.

15. Son DJ, Lee JW, Lee YH, Song HS, Lee CK, Hong JT. Therapeutic application of anti-arthritis, painreleasing, and anti-cancer effects of bee venom and its constituent compounds. Pharmacol Ther. 2007;115(2):246-70.

16. National Research Council. Guide for the care and use of laboratory animals. 8th ed. Washington: The National Academic Press; 2011. Available from: http:// grants.nih.gov/grants/olaw/Guide-for-the-care-anduse-of-Laboratory-animals.pdf.

17. Farookhi R, Hemmings R, Brawer JR. Unilateral ovariectomy restores ovulatory cyclicity in rats with a polycystic ovarian condition. Biol Reprod. 1985;32(3):530-40.

18. Luo H, Zuo XX, Li T, Zhang J. Effect of bee venom on adjuvant induced arthritis in rats. Zhong Nan Da Xue Xue Bao Yi Xue Ban. 2006;31(6):948-51.

19. Demissie M, Lazic M, Foecking EM, Aird F, Dunaif A, Levine JE. Transient prenatal androgen exposure produces metabolic syndrome in adult female rats. Am J Physiol Endocrinol Metab. 2008;295(2):E262-8.

20. Liu N, Liu J, Ji Y, Lu P, Wang C, Guo F. C - reactive protein induces TNF- $\alpha$ secretion by p38 mapk-tlr4 signal pathway in rat vascular smooth muscle cells. Inflammation. 2011; 34(4):283-90.

21. Spaczynski RL, Arici A, Duleba A. Tumor Necrosis Factor-alpha stimulates proliferation of rat ovarian theca-interstitial cells. biology of reproduction. 1999;61(4):993-8.

22. González F, Rote NS, Minium J, Kirwan J. Increased activation of nuclear factorB triggers inflammation and insulin resistance in polycystic ovary syndrome. J Clin Endocrinol Metab. 2006;91(4):1508-12.

23. Nakanuma Y, Tsuneyama K, Harada K. Pathology and pathogenesis of intrahepatic bile duct loss. J Hepatobiliary Pancreat Surg. 2001;8(4):303-15.

24. Repaci A, Gambineri A, Pasquali R. The role of lowgrade inflammation in the polycystic ovary syndrome. Mol Cell Endocrinol. 2011;335(1):30-41.

25. Cortón M, Botella-Carretero J, Benguría A, Villuendas G, Zaballos A, San Millán J, et al. Differential gene expression profile in omental adipose tissue in women with polycystic ovary syndrome. J Clin Endocrinol Metab. 2007;92(1):328-37.

26. Nam KN, Je KH, Lee JH, Han HJ, Lee HJ, Kang SK, et al. Inhibition of COX-2 activity and proinflammatory cytokines (TNF-alpha and IL-1 beta) production by 
water- soluble sub-fractionated parts from bee (Apis mellifera) venom. Arch Pharm Res. 2003;26(5):383-8.

27. Tan BK, Adya R, Chen J, Farhatullah S, Heutling D, Mitchell D, et al. Metformin decreases angiogenesis via NF-kappaB and Erk1/2/Erk5 pathways by increasing the antiangiogenic thrombospondin-1. Cardiovasc Res. 2009;83(3):566-74.

28. Velija-Asimi Z. Metformin decreases CRP level and cardiovascular risk in PCOS women. Endocrine Abstracts. 2006;11:705.
29. Morin-Papunen L, Rautio K, Ruokonen A, Hedberg P, Puukka M, Tapanainen J. Metformin reduces serum C-reactive protein levels in women with polycystic ovary syndrome. J Clin Endocrinol Metab. 2003; 88(10):4649-54.

30. Dandona P, Aljada A, Ghanim H, Mohanty P, Tripathy C, Hofmeyer D, et al. Increased plasma concentration of macrophage migration inhibitory factor (MIF) and MIF mRNA in mononuclear cells in the obese and the suppressive action of metformin. J Clin Endocrinol Metab. 2004; 89(10):5043-7. 